\title{
Un viaje a las Fortunatae Insulae
}

\author{
Antonio Tejera Gaspar \\ Catedrático de Arqueología \\ http://doi.org/10.31939/bierehite/2019.02
}

Pretendo en esta intervención hacer una reflexión sobre algunas cuestiones del texto de Plinio el Viejo (Caius Plinius Secundus), sobre las Islas Afortunadas (Fortunatae Insulae) que se halla recogido en los parágrafos 202-205 del libro VI de su Historia Natural INaturalis Historial, que fue escrita en el último tercio del siglo I de la Era, en época del emperador Vespasiano.

La exploración del Mar Exterior o mar Atlántico en la Antigüedad, está llena de referencias contradictorias porque en ella se mezclan las alusiones míticas a un mar, secularmente desconocido, cuando comenzó a ser explorado, ya bien avanzado el primer milenio de la era. El texto que a mi juicio define mejor la fusión de lo que se ha denominado literatura paradoxográfica, fantástica o imaginada, respecto de la geografía real es, a no dudarlo, el Periplo de Hanón, que unas veces se ha clasificado de relato mítico, y otras muchas, las más, como un derrotero donde, según un buen número de analistas, contiene una descripción precisa y detallada del litoral africano que alcanzaría hasta las costas del golfo de Guinea. No es este el lugar para entrar en esa discusión sobre la que ya hemos publicado un trabajo con Esther Chávez Álvarez', donde defendemos que este primer derrotero del Atlántico africano es, a nuestro

1 TEJERA GASPAR, Antonio; CHÁVEZ ÁLVAREZ, María Esther "El periplo de Hanón y las Islas Canarias". Estudios de Prehistoria y Arqueología en homenaje a Pilar Acosta Martínez / coord. por Rosario Cruz-Auñón Briones, Eduardo Ferrer Albelda, 2009, págs. 395-406. 
parecer, muy preciso y fiable, al menos desde los parágrafos 1 al 8, donde se incluyen los islotes de Mogador en los que se ha confirmado, a través de una serie de estudios arqueológicos allí realizados desde la década de los años cincuenta del siglo pasado, una ocupación temporal de los fenicios. Este lugar se correspondería con la denominada isla de Cerne que figura en el periplo, y que en otras épocas ha sido ubicada en los sitios más dispares, siempre de manera aleatoria, ya que los analistas seleccionaron al azar los accidentes geográficos que en cada caso les parecían más apropiados para vincularlo con aquella.

Esta isla de Cerne (Kerne) se correspondería con una de las que forman el pequeño archipiélago marroquí de Mogador, en Essauira, según los estudios de M. Kbiri Alaoui y Fernando López Pardo², quienes demostraron el origen de su nombre, cuerno, que procedería de una palabra de etimología griega, Kerne, con la particularidad de que su forma se asemeja, precisamente, a la del islote de mayores dimensiones. Las características a las que alude el texto son, pues, muy precisas, y complementan lo aportado por los restos arqueológicos de origen fenicio, fechados desde mediados del siglo VII (650 a.C.), a la mitad de la centuria siguiente (550 a.C.), que sería confirmada, asimismo, por los trabajos que han sido coordinados por la Dra. Dirce Marzoli ${ }^{3}$, directora del Instituto Arqueológico Alemán de Madrid. Todos han ratificado los que se habían realizado en la década de los cincuenta del siglo XX, permitiendo, además, que se pudiera verificar la pertenencia de estos islotes a las que se conocen como Islas Purpurarias, citadas, igualmente, en el texto pliniano, “...que unas pocas, descubiertas por

2 KBIRI ALAOUI, M. y LÓPEZ PARDO, F. (1998): "La factoría fenicia de Mogador (Essauira, Marruecos): Las cerámicas pintadas”, Archivo Español de Arqueología, 71, pp. 5-25.

3 Mogador (Essaouira), Marokko. Ein phönizischer Außenposten an der marokkanischen Atlantikküste. Die Arbeiten der Jahre bis 2018. DAI. publications. ELEKTRONISCHE PUBLIKATIONEN DES DEUTSCHEN ARCHÄOLOGISCHEN INSTITUTS. 
Juba, están en el meridiano de los autóloles, en las cuales había establecido factorías para teñir la púrpura getúlica" $(\mathrm{NH}, 200)^{4}$.

El descubrimiento y la navegación por las costas atlánticas africanas, es una cuestión muy destacada de la historia marítima de la Antigüedad, con la que se asocia, también, el conocimiento de las islas Canarias -las Fortunatae Insulae- que forman un capítulo nada desdeñable, del mismo modo que el Periplo de Hanón, ya que en ellas se mezclan los viejos mitos del mundo grecorromano con un espacio geográfico real, pero que por esas fechas les era desconocido, y solo se verificaría en torno al siglo I a.C. y I d.C. El citado texto de Plinio nos aporta en este sentido un buen argumento para confirmar la realidad de estas islas, a pesar de que aún se mezcle alguna alusión a los mitos clásicos, como la isla Ombrios.

El primer acercamiento que nos parece necesario realizar sobre el descubrimiento de las islas Canarias en la Antigüedad, ha de ser el de analizar, primeramente, los problemas de la navegación por el Atlántico, al sur de las islas de Mogador que, como hemos visto, ya fueron conocidas por los fenicios, al menos desde mediados del siglo VII a.C. Por esta razón, en un proyecto de investigación que dirige la profesora Chávez Álvarez, y del que también formo parte, participa, además, el profesor Antonio Ceferino Bermejo Díaz, profesor de la Facultad de Náutica y Transporte marítimo de la Universidad de La Laguna. La hipótesis de partida es, sobre todo, la de resolver los problemas inherentes a la navegación por el Atlántico en la Antigüedad. Se trata, a nuestro juicio, de una cuestión esencial, toda vez que para alcanzar las islas, ya sea desde el puerto de Cádiz, o de los islotes de Mogador, hay que recorrer una distancia superior a unos 1.500 kilómetros de Cádiz, o unos 450 kms desde Mogador, después de atravesar una navegación muy difícil, como 
pudo comprobarlo Cristóbal Colón, cuando el día 6 de Agosto, tres días después de la salida el viernes 3 , desde el puerto onubense de Palos, se le había roto el timón de la Pinta, hasta tanto pudo refugiarse en la isla de Gran Canaria.

La primera cuestión a resolver para realizar un viaje a las Afortunadas en época antigua, consistiría, pues, en definir ¿Cómo era esa navegación? ¿Qué tipo de naves podrían hacer ese recorrido? además de manejarse otra serie de factores sobre las características del mar en el que se ha de navegar, conocer las corrientes marinas y los vientos, de octubre a abril, época en la que se hacían las travesías marítimas en la Antigüedad. Es imprescindible, conocer, además, el tipo de embarcaciones y sus pertrechos, como el uso de la vela cuadra o cuadrada, como los remeros necesarios para realizar un recorrido de esas características, del modo que se hizo, igualmente, en las galeras de la Baja Edad Media hasta el siglo XVI.

Antes de hacer algunas consideraciones sobre el texto citado, he de decir que lo contenido en él responde, a mi juicio, a la descripción precisa de islas reales en el Atlántico que coincide, sin ninguna duda, con las del Archipiélago Canario, como así lo han defendido un considerable número de estudiosos ${ }^{5}$, entre quienes existe un cierto acuerdo sobre la veracidad de lo que nos fue transmitido por Plinio el Viejo. Uno de esos aspectos, y no el de menor entidad, desde luego, es el referido a las distancias que hubieron de recorrer las naves, ya fuera, como he señalado, de Cádiz o de Mogador,

5 ÁLVAREZ DELGADO, J. (1945 a): «Las islas Afortunadas en Plinio», Revista de Historia, 69, pp. 26-61. José A. DELGADO DELGADO, Canarias en la antigüedad como problema histórico, Tabona: Revista de Prehistoria y de Arqueología, No , 19, 2011-2012, págs. 9-23. DÍAZ TEJERA, A. (1988): "Las Canarias en la Antigüedad", en F. Morales Padrón (Ed.), Canarias y América, Sevilla, pp. 13-32. GARCÍA GARCÍA, A. (2008): «El informe de Juba II sobre las Fortunatae Insulae (Plinio el Viejo, HN- VI, 202-205)», Tabona 17, pp. 141-164. GARCÍA GARCÍA, A., TEJERA GASPAR, A. (2014): «La primera imagen de las Islas Canarias en la Naturalis Historia de Plinio el Viejo», Fortunatae, 25, pp. 157167. Francisco GARCÍA-TALAVERA CASAÑAS, Purpurarias afortunadas: la Macronesia 
como ha sido contrastado en el estudio de A. Santana et alii ${ }^{6}$, donde confirman la exactitud de las distancias que se hallan recogidas en el texto.

Cayo Plinio el Viejo conocía muy bien cómo se navegaba porque, no en vano, había sido jefe de la armada romana en Misena, en el golfo de Nápoles, por lo que sabía en cada momento las distancias que habrían recorrido las naves, la manera de orientarse, la separación de la tierra a la que se encontraban las embarcaciones, así como destacando siempre los datos más precisos y singulares de los lugares que iban reconociendo, como se aprecia muy bien en el texto.

La información sobre las islas Afortunadas contenida en la Historia Natural, fue compilada por Plinio el Viejo de todo el conocimiento que pudo reunir. Había nacido en el siglo I d.C., el año 23, a poco de la muerte de Juba II. Ambos acontecimientos habían coincidido con el mandato del emperador Tiberio. Su muerte fue causada por los gases producidos en la erupción del Vesubio, junto a la ciudad de Pompeya (Nápoles), el 24 de agosto del año 79, mientras observaba el fenómeno volcánico, según el relato que conocemos por su sobrino Plinio el Joven, quien dio cuenta de todos estos aconteci-

Central en la Antigüedad, Makaronesia: Boletín de la Asociación de Amigos del Museo de Ciencias Naturales de Tenerife, №. 8, 2006, págs. 60-8. JIMÉNEZ GONZÁLEZ, J.J. (2014): La tribu de los CANARII. Arqueología, Antigüedad y Renacimiento, Santa Cruz de Tenerife, Le Canarien ediciones. MARTíNEZ HERNÁNDEZ, M (1996): Las Islas Canarias de la Antigüedad al Renacimiento. Nuevos aspectos, Santa Cruz de Tenerife, Centro de la Cultura Popular Canaria. MEDEROS MARTíN, A., ESCRIBANO COBO, G. (2014): Descubrimiento, colonización y primer poblamiento de las Islas Canarias de Juan Álvarez Delgado, Eds: Alfredo Mederos Martín y Gabriel Escribano Cobo, Santa Cruz de Tenerife, Ediciones Idea. Col. Thesaurus. SANTANA SANTANA, A., ARCOS PEREIRA, T., ATOCHE PEÑA, P., MARTíN CULEBRAS, J. (2002): El conocimiento geográfico de la costa noroccidental de África en Plinio: la posición de las Canarias, Ed. Georg Olms Verlag Hildesheim, Zürich, New York.

6 SANTANA SANTANA, A., ARCOS PEREIRA, T., ATOCHE PEÑA, P., MARTíN CULEBRAS, J. (2002): 230. 
mientos en las cartas que le escribió al emperador Trajano.

De las fuentes que habría manejado sobre las islas Afortunadas, podemos clasificarlas en tres grupos, tal como él mismo las expone. Alude en primer lugar a unos datos, de los que no sabemos su procedencia, y que se solapan bajo la expresión "Hay quienes". Sin embargo, es más explícito cuando se refiere, de forma expresa, a la documentación procedente de algún informe elaborado por Estacio Seboso, personaje de escaso perfil biográfico, pero del que sabemos vivió "un poco anterior a Juba, amigo de Cátulo, viajero incansable y que reunió sus conocimientos, en una extensa obra, sólo conocida por referencias, como en este caso por Plinio", que debió de haber vivido en torno al año 35 a. $C^{7}$., lo que nos hace pensar, como posible, que por esos años se podrían haber descubierto las islas. No deja de ser más que una hipótesis sin mucho fundamento, ya que se trata de un tema cuya discusión necesita de un análisis más riguroso que no es posible plantear aquí. Y, por último, la información más completa es la que procede de Juba II de Mauritania, quien desempeña el papel más destacado en cuanto al contenido de este texto, $y$, sin duda, un personaje fundamental en todos estos acontecimientos que se hallan asociados a la historia de su reinado. Había nacido el año 50 a.C., durante la República y muerto el año 23 d.C. La información aportada por Juba II, rey de la Mauritania, se encontraba en su libro perdido Sobre Libia. En él se recogía el relato de una expedición que se había realizado con el fin de conocer los territorios de su jurisdicción ${ }^{8}$, ya que era imprescindible saber lo que existía al sur de Mogador, lugar en donde, como hemos visto, ya se habían asentado los fenicios. Sin embargo, a partir de aquí hacia el sur, toda la costa era terra incognita, aún no explorada por los romanos. Se trataba de una expedición estraté-

7 Alberto DÍAZ TEJERA, ob. cit: 14; José A. DELGADO DELGADO, "Canarias en la antigüedad como problema histórico", Tabona, nº, 19, 2011-2012, págs. 9-23.

8 GARCÍA GARCÍA, A. (2010): Juba Il y las Islas Canarias, Santa Cruz de Tenerife, Ediciones Idea. 
gica para conocer las riquezas que encerraba ese inmenso litoral al sur de Mogador, en donde se suponía podrían existir algunos asentamientos fenicios. Hoy, por el contrario, sabemos que en esa zona no se ha documentado ningún asentamiento, a pesar de todos los intentos que se han realizado. En este contexto, Juba vuelve a reconocer las islas que ya habría descubierto Estacio Seboso, como parece desprenderse de una referencia de Leonardo Torriani relativa a estos acontecimientos, cuando dice que «algunos pretenden que estas islas quedaron después desiertas y casi desconocidas, durante muchos años, y que más tarde las volvió a descubrir Juba y las pobló con númidas.»" En este contexto histórico, la alusión de Torriani me parece de un extraordinario interés, sobre todo porque de esa forma el texto cobra sentido y nos ayuda a entender cómo debió de haberse producido el descubrimiento de las islas. Y del mismo modo que hemos hecho con relación a la exploración en la que intervino Estacio Seboso, podemos preguntarnos cuándo tuvo lugar la expedición mandada por Juba ¿El año 18 a.C., el 12 a.C.? ¿En el primero antes de la era? ¿Después de la era?... Como es de suponer, nada sabemos cuándo se produjo. Por todo lo dicho, es frecuente referirse al texto pliniano con la denominación de "Plinio-Juba". No obstante, siguiendo ese mismo criterio, podríamos referirnos a él, asimismo, como de "Plinio-Estacio-Juba", porque de ambos autores tomó prestada información el naturalista latino, y porque si seguimos un orden cronológico los datos aportados por Seboso fueron, evidentemente anteriores a los de Juba, y al que habría de considerarse el primer descubridor de las islas de quien conservamos su nombre.

Sobre los informantes anónimos se alude a ellos en el primer párrafo que se inicia con una expresión latina muy vaga, Qui sunt...: "Hay quienes piensan que más allá de éstas [las islas Purpura-

9 TORRIANI, L. ([1590]/1978): Descripción e historia del reino de las Islas Canarias. Introducción y Notas por Alejandro Cioranescu, Santa Cruz de Tenerife, Goya Ediciones. Capítulo IV, «Quiénes fueron los primeros habitantes de estas islas», p. 20. 
rias] se encuentran las Afortunadas y algunas otras..." Es de suponer que esta información procedería de algunos marinos que, con anterioridad a lo aportado por Estacio Seboso y Juba, debieron de haber realizado distintas exploraciones por la costa africana, lo que hace suponer que fueran ellos quienes darían cuenta primeramente de su existencia, aunque nada sabemos con certeza de quiénes fueron, ni cómo obtuvieron ese conocimiento.

Resulta evidente que, a pesar de lo poco explícito del texto, se puede deducir, en efecto, la presencia de unos primeros exploradores desconocidos, por lo que nos parece muy destacada la puntualización que al respecto hace el profesor Díaz Tejera, cuando dice que "Ombrios no tiene nada que ver, lingüísticamente, con Aprósitos. Mas, a su vez, hay que decir que Aprósitos tampoco tiene relación con ningún otro nombre dado por Plinio, lo que implica que Ptolomeo, al menos en este punto, conoce una fuente que no es Plinio." ${ }^{10}$ Esta referencia pone en evidencia la existencia de esas otras fuentes que se hallan, igualmente perdidas, pero que nos pone en la pista de otros exploradores, como ya había puesto de manifiesto Álvarez Delgado sobre la posibilidad de que las islas hubieran sido previamente exploradas por marinos gaditanos, de los que sugiere el nombre de uno de ellos, el navegante y geógrafo griego Eudoxo de Cícico (ca. 150 a. C. - ca. 100 a. C.), de quien se cree habría intentado circunnavegar África, a pesar de no haberlo conseguido. Como complemento a lo que vengo expresando, me parece que conviene tener en cuenta, asimismo, que en las últimas líneas del texto pliniano se dice que en la isla de Canaria “... aparecen vestigios de edificación," lo que me ha hecho suponer si esta referencia pudiera estar relacionada de alguna manera con la presencia de esos otros marineros y exploradores que hubieran conocido las islas con anterioridad, como así sucedió con muchas islas del Pacífico, descubiertas por expedicionarios españoles y más tarde abandonadas, pero habitadas durante algún tiempo, lo

10 Alberto Díaz Tejera, ob. cit., p. 25. Véase, asimismo, J.A. Delgado, ob. cit. 
que hace suponer una estancia temporal de la que habrían quedado algunos vestigios. Advierto al lector que lo dicho no deja de ser más que una especulación, y como tal ha de considerarse, porque no cuento con ningún dato veraz que me permita sostener lo aquí expuesto. Por último, la información del texto se completa con lo aportado por Estacio Seboso y, sobre todo, por el informe de la exploración que mandó realizar Juba II de Mauritania.

Una de las cuestiones sobre la que ha existido siempre una gran discusión es la relativa a la ruta seguida por los primeros descubridores de las islas Canarias. Como quiera que las islas más orientales del Archipiélago como Lanzarote y, sobre todo, Fuerteventura se encuentran cercanas a la costa africana, es de suponer que fuera esta travesía por donde primero pudo producirse este descubrimiento. Sin embargo, una lectura detenida de lo que se ha conservado en el texto que analizamos, parece contradecir esta opinión, ya que la ruta seguida por las naves hasta alcanzar las islas fue por occidente, ya que fueron ellas las que se avistaron en primer lugar hasta alcanzar más tarde Tenerife y Gran Canaria. Esta es, sin duda, la singladura que, en efecto, figura en el texto, que partió de la costa marroquí de Essauira-Mogador después de adentrarse en el mar, navegación por cierto que debieron de conocer con bastante exactitud, entre otras cosas, porque es más segura que la del costeo por el litoral africano. La travesía del Oeste es, en efecto, la que figura descrita en el texto de manera precisa, y en la que, por cierto, debió desempeñar un papel importante la pronta visión del Teide, ya que, como es bien sabido, los navegantes han comprobado que es posible columbrarlo desde una distancia muy lejana, y les sirve de referencia para marcar la orientación y el rumbo que han de seguir. En la navegación antigua era frecuente contar siempre con un accidente singular de referencia a partir del que tenían la seguridad de que se podría alcanzar el lugar al que se dirigían las naves de una expedición. Me parece que el Teide actuaría aquí como faro que eles quiaba en la distancia. Por eso, la alusión que a él se hace en 
tener, asimismo, esta otra valoración, cuando se dice que “.... a la vista de ellas está Ninguaria, siempre cubierta de nieblas y que recibió tal nombre de las nieves perpetuas." La imagen descrita en esta línea sobre la isla -aunque debemos entender que se está refiriendo al Teide- es que de este modo se veía a la distancia. Una masa enorme que debido a su altitud sobresalía por encima de las nubes. Este faro natural fue, pues, la guía que facilitaría acercarse a las islas, como sucede desde hace siglos, de modo que se puede navegar teniendo en lontananza esa referencia segura y precisa: "a condición de que, primero se navegue una distancia de $\mathbf{2 5 0}$ millas en dirección norte-poniente y, después, se viaje a otra distancia de $\mathbf{3 7 5}$ millas en dirección naciente y que la primera isla que se alcanza se denomina Ombrios. (...) Que la segunda isla es llamada Junonia (..). Y que en la cercanía de ésta se halla otra del mismo nombre pero menor y luego se encuentra Capraria (...) ... a la vista de ellas está Ninguaria, siempre cubierta de nieblas y que recibió tal nombre de las nieves perpetuas. Muy próxima a esta isla se dice está Canaria...".

Además de la ruta señalada que figura en el texto, debió de existir otra más antigua que quizá fuera la que daría lugar al primer descubrimiento de las islas, como he dicho. Me refiero a la alusión que se hace en el texto sobre las Afortunadas que las ubica “.... 250 millas de estas dos islas [Pluvialia y Capraria], las Afortunadas se encuentran frente a la costa izquierda de Mauritania y hacia el suroeste y que una se llama Invallis y la otra Planasia por su aspecto". Esas 250 millas equivalen a unos $375 \mathrm{~km}$ que sería la distancia aproximada desde La Palma hasta Lanzarote y Fuerteventura, de manera que tanto aquella como la ubicación al suroeste de la costa izquierda del litoral africano, no parecen dejar dudas de que se trata de las dos islas orientales, a las que singulariza con los nombres de Invallis y Planasia"1 , denominación que podría pro-

11 El profesor Díaz Tejera, ob.cit. p. 21, sugiere que el nombre Invalis pudiera ser Niva- 
ceder esta última de uno similar a la actual Pianosa, cuyo nombre antiguo era también Planasia, y que se encuentra ubicada al oeste del mar de la Liguria en Italia, a la altura de la Toscana.

Y ¿por qué en este texto se cita a las Afortunadas?, como islas diferenciadas. Yo pienso que esta referencia alude a que, con casi toda seguridad, mucho antes ya se habían descubierto, seguramente en viajes de costeo por el litoral africano, cuando se encontraron con Lanzarote y Fuerteventura, y a las que denominarían Afortunadas, como así sucedió cuando entre el año 82 y 81 a.C., el General Sertorio que se hallaba por esa fecha en la península Ibérica, durante las guerras civiles de Mario y Sila, conoció en Cádiz a unos pescadores que habían descubierto dos islas situadas muy cerca de África, a las que denominaron "las Afortunadas", el lugar adonde iban a parar las almas de los bienaventurados o afortunados, de manera que esta antigua denominación mitológica, así como su ubicación, se iría alejando a medida que iban conociendo las nuevas tierras que se iban explorando. Y en mi opinión, aquellas dos islas primeras coincidirían con las de Mogador, descubiertas por los romanos en las fechas arriba indicadas y que más tarde se lo aplicarían a estas dos del archipiélago canario, del mismo modo que siglos más tarde, en el primer tercio del siglo XIV, el genovés Lancelotto Malocello conoció estas islas orientales hasta que en 1341, en la expedición de Nicoloso da Recco descubrieron el resto del Archipiélago, y a las que consideraron las islas nuevamente descubiertas, aquellas que muchos siglos antes habían conocido los romanos.

lis, debido a una posible corrupción del manuscrito, en el que la I podría confundirse con una N, como es muy común en los inicios de palabra, y donde pudiera decir Nivalis, que relaciona con Tenerife, pero el hecho de que las Afortunadas están cerca de África, los nombres de Nivalis y Planasia, serían en ese caso Lanzarote y Fuerteventura. 


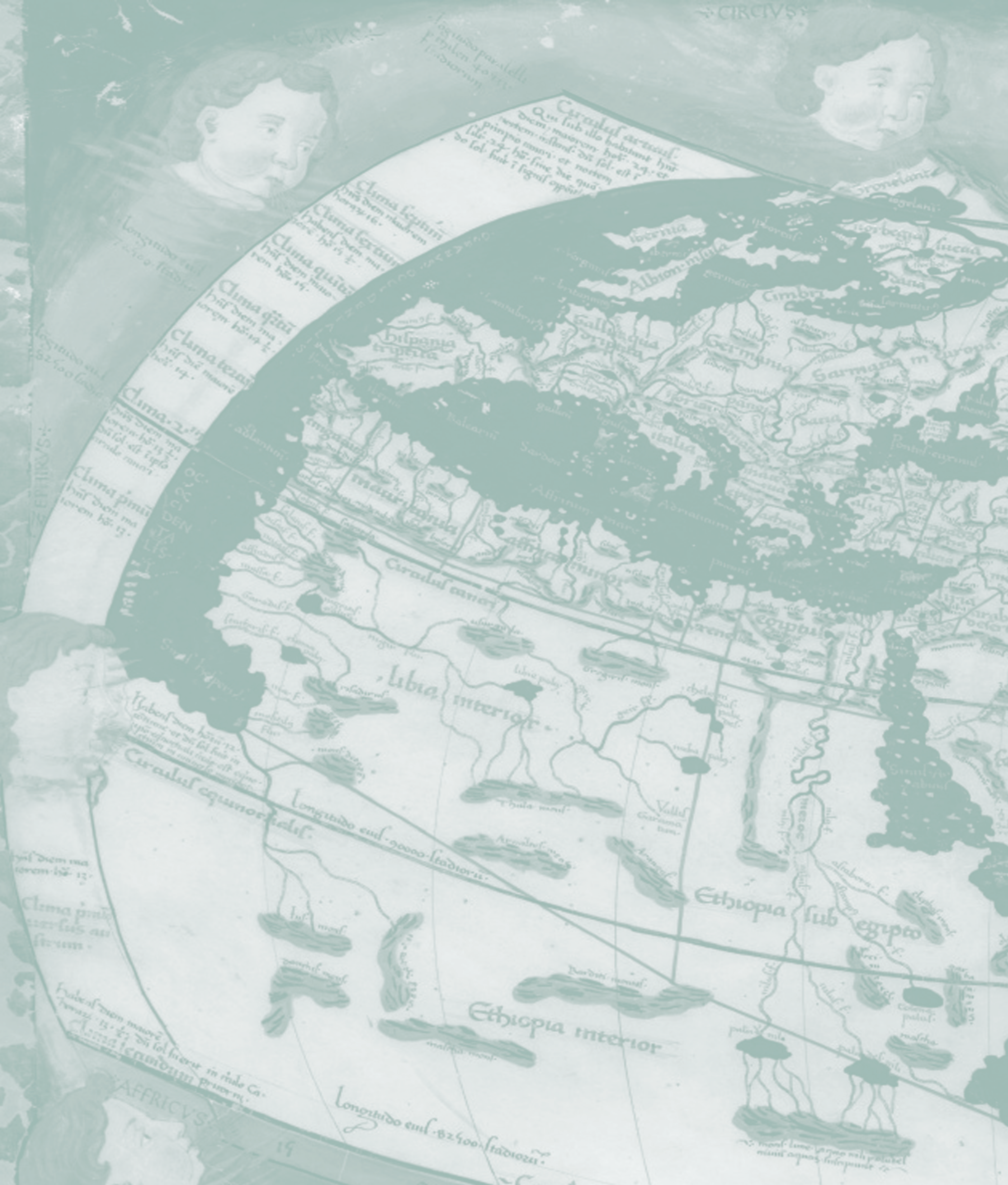

